\title{
Estimation of Phenolic and Flavonoid Compounds and Antioxidant Activity of Spent Coffee and Black Tea (Processing) Waste for Potential Recovery and Reuse in Sudan
}

\author{
Samar A. Abdeltaif ${ }^{1}$, Khitma A. SirElkhatim ${ }^{1}$ and Amro B. Hassan ${ }^{1,2, *(D)}$ \\ 1 Environment and Natural Resource and Desertification Research Institute (ENDRI), \\ National Center for Research, P.O. Box 6096, 11111, Khartoum, Sudan; asmaica24@gmail.com (S.A.A.); \\ khitmaamustafa@gmail.com (K.A.S.) \\ 2 Institute of Geography, Faculty of Science, University of Bern, Hallerstrasse 12, 3012 Bern, Switzerland \\ * Correspondence: amro.eltayeb@giub.unibe.ch or amrobabiker@yahoo.com; \\ Tel.: +41-316-313-856 or +24-911-492-8606
}

Received: 3 April 2018; Accepted: 11 June 2018; Published: 12 June 2018

\begin{abstract}
This study aimed to evaluate the antioxidant power associated with spent coffee and black tea processing waste. Ethanolic extracts from the samples were prepared in order to determine the quantities/concentrations of the phenolic and flavonoid compounds, polyphenols, and associated levels of antioxidant activity. The results showed that both the spent coffee and black tea waste had high amounts of phenolic compounds and high antioxidant activity rates. The total phenolic and flavonoids content was found to be significantly higher $(p<0.05)$ in the spent black tea than in the spent coffee. The total phenolic content was found to be 152.8 and $97.87 \mathrm{mg}$ of gallic acid equivalent/g, while the total amount of flavonoids was found to be 47.40 and $34.32 \mathrm{mg}$ catechin/g in spent black tea and coffee, respectively. However, the spent coffee had a significantly higher $(p<0.05)$ antioxidant activity than that detected in the spent black tea (57.83\%). Consequently, the results revealed that the waste residue of spent coffee and black tea may be considered as natural sources of bioactive compounds and that there may be potential for recycling these waste products, which could be applied in different industries to further develop functional foods.
\end{abstract}

Keywords: coffee; black tea; waste; phenolic; flavonoids; antioxidants activity

\section{Introduction}

Recently, wasted food has received more consideration in both academic and social interest groups in developed and developing countries. The interest and concern stem from the annual increase in the amount of food waste that is expected to reach about 126 Metric tons in the next few years [1]. Such a notable increase in the rate of waste production has a negative impact on the environmental, economic, and social sectors. In response to these observations, several policies and actionable recommendations have focused on recycling and the production of natural bioactive compounds from food waste as potential solutions [2]. Generally, the waste that is produced from the food manufacturing processes is considered as a viable potential source of natural bioactive compounds with a high antioxidant power. These compounds, which include phenolic compounds and other phytochemical compounds, have high-value products and their recovery may be economically attractive [3-5]. Moreover, they have nutritional and health benefits for humans. Besides these benefits, antioxidants have important contributions to the food industry. They are capable of preventing the propagation reaction during the oxidation process, which results in maintaining the quality and shelf-life of food products during 
handling and storage [6,7]. Furthermore, these compounds can be reused as natural and functional additives, since they are natural, inexpensive, and available in enormous amounts [8-10].

In recent times, the use of antioxidants extracted from natural, rather than artificial sources, in food manufacturing, has increased as a result of several factors, including health and functional factors. Moreover, additional consideration is being paid to classifying natural compounds as well as their economic application as effective antioxidants in functional food [9,11].

Coffee and tea are considered to be the richest sources of the bioactive compounds, which contain an appreciable amount of antioxidants, flavonoids, and phenolic compounds. Consequently, their processing waste may contain a significant quantity of natural antioxidants [12,13]. It has been determined that the waste from coffee and black tea residue, particularly from the coffee industry, has experienced annual increases of an estimated 6 million tons internationally [14]. Technologies have been developed to recycle coffee and black tea waste by converting this sizable quantity of waste products into new sources of more desirable natural products. Subsequently, there is a need determine the potential feasibility and utility of using recycled by-products from spent coffee and black tea waste, as well as determining the extent of their application in different food processes, so as to manufacture functional foods. In particular, an estimation of the antioxidant capacity of spent coffee and black tea waste is required so as to support the exploration of their potential use as an alternative source of artificial antioxidants in the food industry.

Normally, in Sudan, coffee and black tea are used daily after being prepared in a domestic way, especially by the traditional sellers. Through the survey, we found that the majority of the sellers use the same types of coffee and black tea. Unfortunately, there has been no real data regarding the amount of coffee and tea waste that has been produced by these sellers in Sudan. An accumulation of this waste poses a problem to the environment, as it is prone to microbial spoilage, and therefore, there is a need to upgrade the recycling system in order to evaluate the potential for recycling the by-products from these wastes, to find out the possibilities of their use in different food formulations or the manufacture of health-promoting products or functional foods in Sudan. Therefore, this study has evaluated the capacity of phenolic and flavonoids compounds and determined the antioxidant activity in spent coffee and black tea waste. The assessments were then compared to the findings that were based on raw coffee and black tea.

\section{Materials and Methods}

\subsection{Collection and Preparation of Coffee and Black Tea Samples}

The coffee and black tea samples were purchased from the local market in Khartoum. The waste from the coffee and black tea was prepared according to the domestic method for processing. Subsequently, $50 \mathrm{~g}$ of black tea leaves was brewed in $1000 \mathrm{~mL}$ of hot water $\left(100{ }^{\circ} \mathrm{C}\right)$ for five minutes, followed by filtering and drying processes in an air-dried oven at $45^{\circ} \mathrm{C}$ for $48 \mathrm{~h}$. The coffee was roasted, following the domestic methods for preparing coffee at a household level. The spent coffee was prepared by adding $50 \mathrm{~g}$ of roasted coffee to $100 \mathrm{~mL}$ of water, and it was boiled for $10 \mathrm{~min}$. In order to obtain the dried spent coffee, the same filtration and drying methods that were used to obtain the spent black tea were followed.

\subsection{Preparation of Extracts}

To prepare the extract, the milled sample was mixed with ethanol at a ratio of 1:25 (w/v), and it was then shaken at ambient temperature for $24 \mathrm{~h}$. The mixture was then filtered using a filter paper (Whatman No. 1, Double ring, China). The residue was washed with ethanol and the collected extract was dried under vacuum using a rotary evaporator and kept dry for further analysis. The extracts were reconstituted by pure ethanol directly before the analysis of the total phenolic content and total flavonoids. 


\subsection{Determination of Total Phenolic Content}

The total phenolic content of the samples was determined by the Folin-Ciocalteu's reagent method [15], with slight modification. An aliquot $(20 \mu \mathrm{L})$ of a dried extract ethanolic solution $(1: 10 w / v)$ was added to $1.58 \mathrm{~mL}$ of water and $100 \mu \mathrm{L}$ of the Folin-Ciocalteu reagent. After five minutes, $300 \mu \mathrm{L}$ of the $10 \%$ sodium carbonate solution was added to the mixture and was carefully agitated for $10 \mathrm{~min}$. The mixture was allowed to stand in the dark for two hours at $20^{\circ} \mathrm{C}$. The absorption was measured at $765 \mathrm{~nm}$ using ultraviolet (UV)-spectrophotometer, Jenway, UK. Different concentration of gallic acid dissolved in pure ethanol were used to prepare the calibration curve $\left(R^{2}=0.9672\right)$. The total phenolic content was expressed as milligrams of gallic acid equivalent per gram of dried samples (mg GAE/g DW).

\subsection{Determination of Total Polyphenols}

The polyphenols of each sample were estimated using Prussian blue assay, as described by Price and Butler [16]. About $60 \mathrm{mg}$ of the ground sample was extracted, with $3 \mathrm{~mL}$ methanol in a $50 \mathrm{~mL}$ conical flask, and then poured into a filter paper. The tube was quickly rinsed with an additional $3 \mathrm{~mL}$ methanol and the content was poured once into the filter paper. The filtrate was diluted to $50 \mathrm{~mL}$ with distilled water and was mixed with $3 \mathrm{~mL} 0.1 \mathrm{M} \mathrm{FeCL}_{3}$ in $0.1 \mathrm{~N}-\mathrm{HCL}$ for three minutes, followed by a timed addition of $3 \mathrm{~mL} 0.008 \mathrm{M} \mathrm{K}_{3} \mathrm{Fe}(\mathrm{CN})_{6}$. The mixture was allowed to stand for $10 \mathrm{~min}$. The absorption was read at $720 \mathrm{~nm}$ using spectrophotometer.

\subsection{Determination of Total Flavonoids Content}

The total flavonoids content (TFC) of the extracts was measured according to the colourimetric assay of Kim et al. [17]. One milliliter of the ethanolic extract $(1: 10 w / v)$ was added to a $300 \mu \mathrm{L}$ sodium nitrite solution (5\%), followed by $300 \mu \mathrm{L}$ aluminium chloride $(5 \%)$. The mixtures were incubated at room temperature for five minutes, and then $2 \mathrm{~mL}$ of $1 \mathrm{~mol} / \mathrm{L}$ sodium hydroxide was added. Immediately, the volume of the reaction mixture was made to $10 \mathrm{~mL}$ with distilled water and was then thoroughly vortexed. The absorbance of the mixture was determined at $510 \mathrm{~nm}$. A calibration curve was prepared from the different concentrations of catechin $\left(R^{2}=0.974\right)$. The total flavonoid content was reported as milligrams of catechin equivalents, per gram dry weight sample (mg CE/g DW).

\subsection{Determination of Antioxidant Activity}

The scavenging activity of the diphenyl-2-picrylhydrazyl (DPPH) radicals of extract was measured according to the method that was reported by Chang et al. [18], which was cited in Shyur et al. [19]. Assays were performed in $3 \mathrm{~mL}$ reaction mixtures containing $2.0 \mathrm{~mL}$ of $0.1 \mathrm{mM}$ DPPH-ethanol solution, $0.9 \mathrm{~mL}$ of $50 \mathrm{mM}$ Tris-HCl buffer (pH 7.4), and $0.1 \mathrm{~mL}$ of deionized water or sample extract. The absorbance was measured at $517 \mathrm{~nm}$. The capacity to scavenge for the DPPH radical was calculated using the following equation:

Scavenging of $\mathrm{DPPH} \%=[($ Absorbance control - Absorbance sample $) /$ Absorbance control $] \times 100$

\subsection{Statistical Analysis}

All of the data were conducted using a completely randomized block design with at least three replicates. The data were analyzed using a two-way analysis of variance (ANOVA) and the significant differences were calculated $(p<0.05)$ the using least significant difference (LSD). 


\section{Results and Discussion}

\subsection{Phenolic Compounds of Raw and Spent Coffee and Black Tea}

Figure 1 describes the total phenolic content of coffee (raw, roasted, and spent) and black tea (raw and spent tea). It was clearly observed that both the coffee and black tea contained a reasonable amount of phenolic compounds, however, the total phenolic compound in black tea was significantly $(p<0.05)$ higher than that in coffee, which was found to be 104.3 and $187.50 \mathrm{mg}$ GAE /g in raw coffee and black tea, respectively. Similarly, the spent coffee contained less of the total phenolic content (97.87 mg GAE/g) than that in the spent black tea (152.87 mg GAE/g). The analysis of variance showed that there was no significant $(p<0.05)$ difference between the total phenolic in the raw and spent coffee, however, it was found significantly $(p<0.05)$ less in the spent black tea compared with the raw black tea. Previous studies showed that both the coffee and black tea contained a high amount of the phenolic compound. However, the capacity of these compounds depended on several factors, including the varieties and extraction procedures. Geremu et al. [20] reported that a significant variation in the content of the phenolic compound in coffee cherry pulps was observed between different varieties that were extracted by different solvents. According to the previous work of Zuorro and Lavecchia [21], the spent coffee grounds that were collected from coffee bars or recovered from coffee capsules were investigated as a potential source of phenolic compounds and energy. They demonstrated that the total phenolic compound of coffee ranged between 17.75 and $21.56 \mathrm{mg}$ GAE/g.

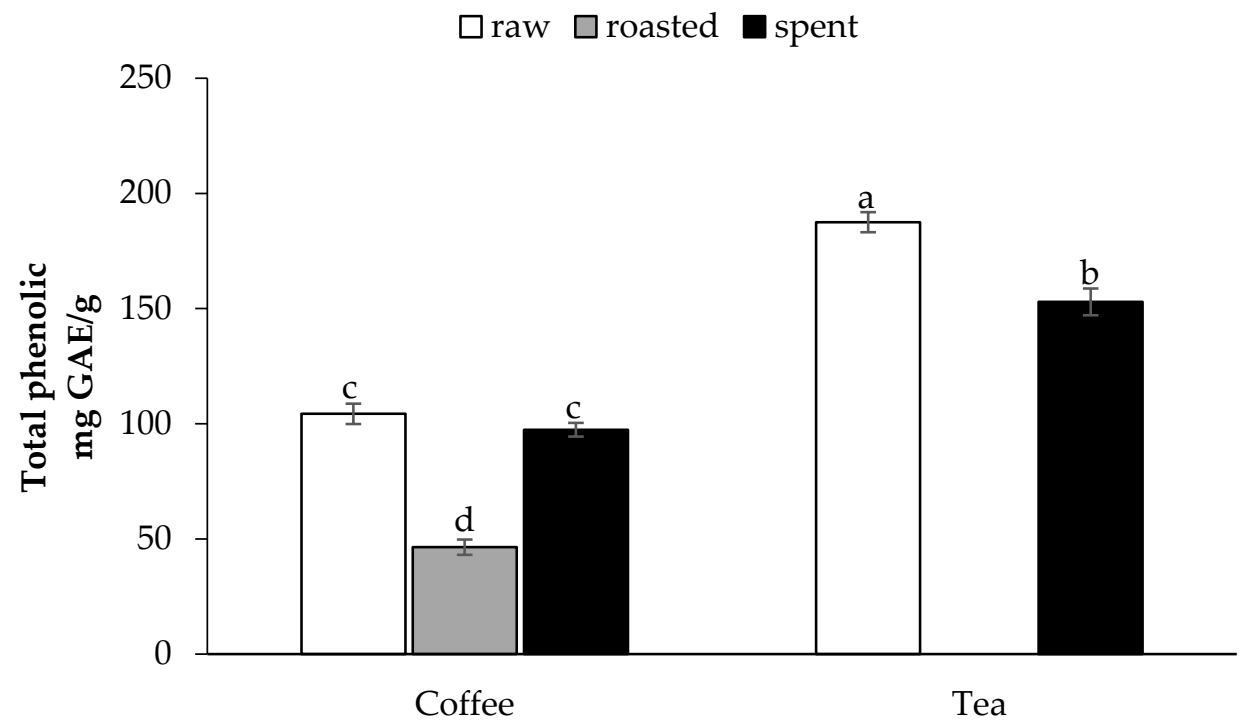

Figure 1. Phenolic content of spent coffee and black tea waste. Data represent the mean \pm standard deviation (SD) $(n=3)$. ${ }^{\text {a-d }}$ Means with different letters are significantly different $(p \leq 0.05)$ as assessed by least significant difference (LSD). GAE—gallic acid equivalent.

Figure 2 shows the content of total polyphenol in raw and spent coffee and black tea. As shown in Figure 2, the total polyphenol content of the raw, roasted, and spent coffee was found to be 43.93, 37.82 and $23.79 \mathrm{mg} / \mathrm{g}$, respectively. The analysis of variance indicated that the total polyphenol was significantly $(p<0.05)$ varied in the raw, roasted, and spent coffee, which might have been influenced by heat treatment. In contrast, the total polyphenol content of the raw and spent black tea was considerably $(p<0.05)$ the same, and it was found to have been 40.35 and $42.52 \mathrm{mg} / \mathrm{g}$ in the raw and spent black tea, respectively. 


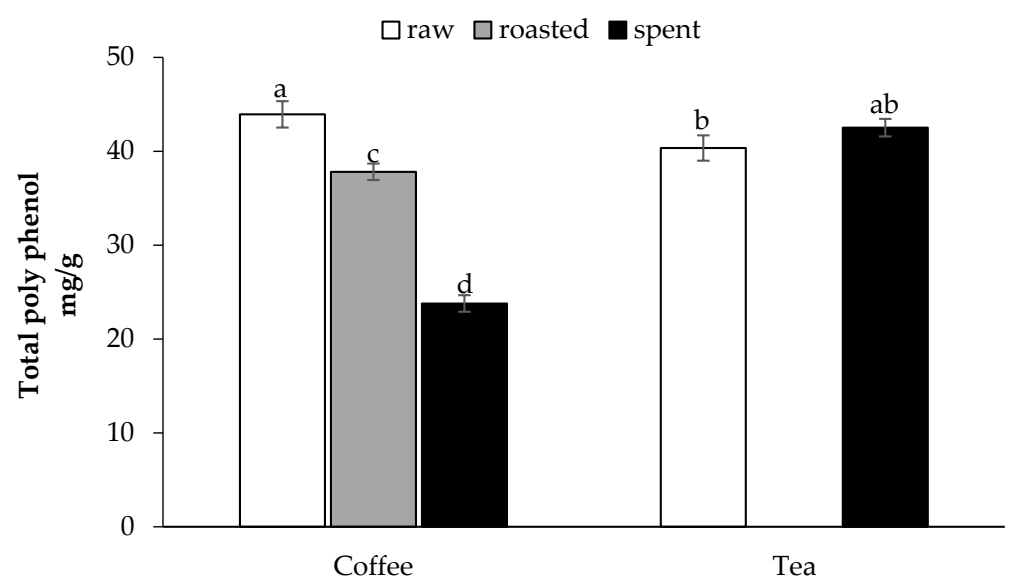

Figure 2. Total polyphenols $(\mathrm{mg} / \mathrm{g}$ ) content of spent coffee and black tea waste. Data represent the mean $\pm \mathrm{SD}(n=3) .{ }^{\text {a-d }}$ Means with different letters are significantly different $(p \leq 0.05)$ as assessed by LSD.

Flavonoids have been considered as the most common, important, and widely distributed single group of phenols that are present in plants with highly effective antioxidants [22]. Flavonoids have inhibited metal-initiated lipid oxidation by forming complexes with metal ions [23]. The content of the total flavonoids of the raw and spent coffee and black tea is seen in Figure 3. The total flavonoid content of coffee and black tea was determined as a form of catechin equivalents. It was cleared that the values of total flavonoids were varied between raw, roasted, and spent coffee. It was found to be 52.07, 30.65, and 34.32 (mg catechin/g), respectively, as seen in Figure 3. The analysis of variance showed that raw coffee contained significantly $(p<0.05)$ higher flavonoids than the roasted and spent coffee, however, there was no significant difference between roasted and spent coffee that was observed. On the other hand, both the black tea and spent black tea contained a similar amount of total flavonoids, which was found to have been 49.57 and 47.40 (mg catechin/g), respectively. In the study that was conducted to compare the content of the antioxidants capacities of different types of raw and spent tea [24], the results showed that both the raw and spent tea contained a high amount of total flavonoids, however, it was found to be less in the spent tea compared with the tea. In general, the variation between our findings and the other results might have been because of the extraction methods, as it was reported that the flavonoid extraction was affected by the extraction method, temperature (above $40^{\circ} \mathrm{C}$ ), and extraction time.

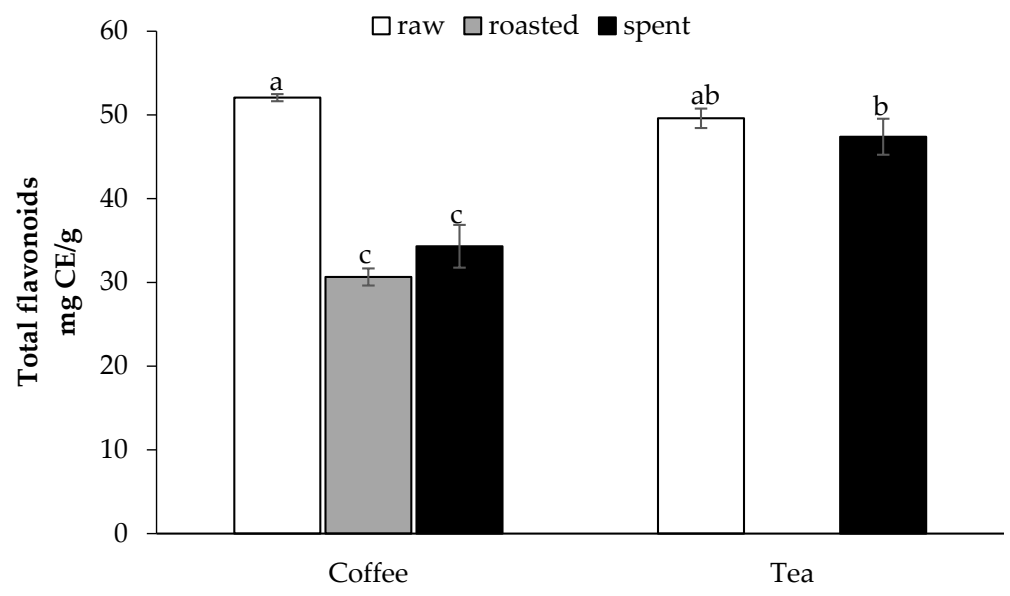

Figure 3. Flavonoids content of spent coffee and black tea waste. Data represent the mean $\pm \operatorname{SD}(n=3)$. ${ }^{\mathrm{a}-\mathrm{c}}$ Means with different letters are significantly different $(p \leq 0.05)$ as assessed by LSD. 


\subsection{Antioxidant Activity of Raw and Spent Coffee and Black Tea}

In this study, the DPPH scavenging method was used to assess the antioxidant activity of the samples. The scavenging model of the DPPH radical was widely used as a method for assessing the antioxidant activity in a period that was relatively short compared with the other methods. Figure 4 displays the antioxidant activity of coffee (raw, roasted, and spent) and black tea (raw and spent), in terms of DPPH scavenging. As shown in Figure 4, the antioxidant activity rate was found to have been significantly $(p<0.05)$ higher in the raw, followed by spent, and then roasted coffee $76.79 \%$, $72.93 \%$, and $59.37 \%$, respectively. The degradation of the antioxidant activity of coffee might have been because of the degradation of the native antioxidants and the formation of new ones during coffee roasting [25]. For black tea, it was observed that the antioxidant activity of the raw and spent was significantly $(p<0.05)$ the same. It ranged between $57.83 \%$ and $59.27 \%$, however, it was significantly lower than the rate of the antioxidant activity in coffee. More or less, the trend that was observed in the DPPH results was the same when comparing the total phenolic compound and total flavonoids content. Thus, fundamentally, the DPPH scavenging ability might have depended on the amount of total phenolic compound and total flavonoids content in the coffee and black tea extracts.

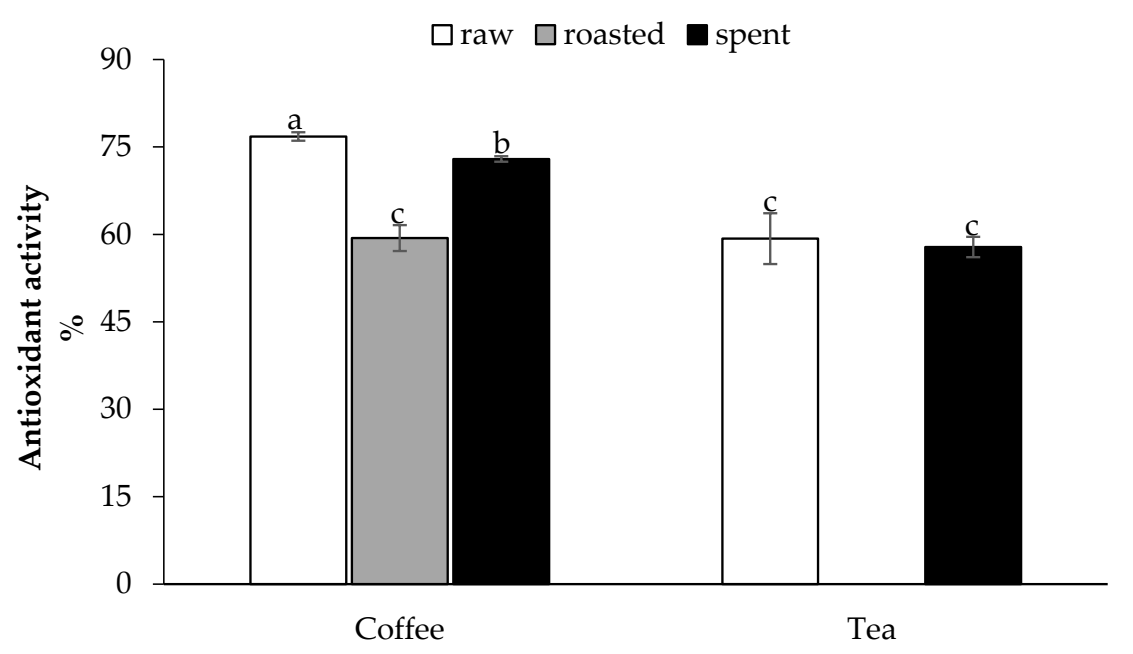

Figure 4. Antioxidant activity of spent coffee and black tea waste. Data represent the mean $\pm S D$ $(n=3) .{ }^{\mathrm{a}-\mathrm{c}}$ Means with different letters are significantly different $(p \leq 0.05)$ as assessed by LSD.

The results were in agreement with the statement that was reported by Lee et al. [20], who stated that the extracts that were enriched with flavonoids or phenolic, showed a much higher DPPH scavenging ability than those of the other extracts. Moreover, Romdhane et al. [26] found that the antioxidant activity of the coffee residual ranged between $64.57 \%$ and $52.83 \%$. Similarly, Farhoosh et al. [27] reported that the old black tea leaves and black tea waste had a high antioxidant activities rate.

The correlation coefficient $\left(R^{2}\right)$ values between the antioxidant parameters in the raw and spent coffee and black tea are shown in Table 1 . From the table, it was clearly observed that there was an appositively high correlation between the antioxidant parameters in the raw and spent coffee and black tea. The correlation values in the parameters between the raw and spent coffee were found to be 0.992 and 0.997 between the raw and spent black tea. On the other hand, the correlation between the coffee and black tea were found to be 0.9078 in the raw samples, and 0.857 in the spent samples. 
Table 1. Correlation coefficient $\left(R^{2}\right)$ between the antioxidants parameters in the raw and spent coffee and black tea.

\begin{tabular}{ccccc}
\hline & Raw Coffee & Spent coffee & Raw Tea & Spent Tea \\
\hline Raw coffee & 1 & & & \\
Spent coffee & 0.9922 & 1 & & \\
Raw tea & 0.9078 & 0.8491 & 1 & \\
Spent tea & 0.9141 & 0.857 & 0.997 & 1 \\
\hline
\end{tabular}

In general, the obtained results revealed that the waste from the processed coffee and black tea contained appreciable amounts of the phenolic compound, as well as a high antioxidant activity rate. The highly positive correlation in the antioxidant parameters between the coffee and black tea waste revealed that they had the potentiality to be an alternative natural resource for the bioactive compounds.

According to Ghafoor et al. [28], the phenolic compounds from natural resources were recommended as natural food additives and they were considered to be more suitable for application in food products compared with artificial compounds that contained antioxidant properties. Moreover, the addition of phenolic in food was also reported for its nutritional and health benefits [29]. Furthermore, a positive correlation between the antioxidant power and total phenolic content indicated that the phenolic compound could be one of the main contributors to the antioxidant capacities of this waste $[30,31]$.

\section{Conclusions}

In conclusion, the values of the phenolic compounds in the spent coffee and black tea were high, indicating that they could be inexpensive and readily available resources of natural bioactive compounds for use in the food industries. Therefore, their wastes could be considered as a good source of bioactive compounds and could be, potentially, applied as a natural antioxidant for developing functional foods. Furthermore, both the spent coffee and black tea may be considered as a low-cost resource for the recovery of phytochemicals, which may have a significant outlook as pharmaceuticals, cosmetic constituents, and food additives, for the industry in Sudan. However, an evaluation of the quality and quantity of the bioactive compounds in coffee and black tea waste is required. In addition, further research, such as the application of different extraction procedures and extraction solvents, will be needed in order to optimize the extraction condition at the industry level. Moreover, the bioactivity, bioavailability, and toxicology of coffee and black tea waste phytochemicals need to be carefully evaluated by in vitro and in vivo studies before considering the likelihood of the reuse of this waste in food industries in Sudan.

Author Contributions: Authors S.A.A. and K.A.S. performed the practical experiments. Author A.B.H. conceived and designed the experiments, analyzed the data, supervised the study and, wrote the manuscript.

Acknowledgments: This study was carried out with the support of the National Center for Research, Sudan (Food Waste Recycling Project).

Conflicts of Interest: The authors declare no conflict of interest.

\section{References}

1. Mirabella, N.; Castellani, V.; Sualeh, S. Current options for the valorization of food manufacturing waste: A review. J. Clean. Prod. 2014, 65, 28-41. [CrossRef]

2. Baiano, A. Recovery of biomolecules from food wastes-A review. Molecules 2014, 19, 14821-14842. [CrossRef] [PubMed]

3. Ajila, C.M.; Naidu, K.A.; Bhat, S.G.; Prasada Rao, U.J.S. Bioactive compounds and antioxidant potential of mango peel extract. Food Chem. 2007, 105, 982-988. [CrossRef] 
4. Kunradi, V.F.G.; da Silva Campelo Borges, G.; Copetti, C.; da Valdemiro Gonzaga, L.; Costa Nunes, E.; Fett, R. Activity and contents of polyphenolic antioxidants in the whole fruit, flesh and peel of three apple cultivars. Arch. Latinoam. Nutr. 2009, 59, 101-106.

5. Hernandez-Carranze, P.; Ávila-Sosa, R.; Guerrero-Beltran, J.A.; Navarro-Cruz, A.R.; Corona-Jimenezi, E.; Ochoa-Velasco, C.E. Optimization of antioxidant compounds extraction from fruit by-products: Apple pomace, orange and banana peel. J. Food Process. Preserv. 2015, 40, 103-115. [CrossRef]

6. Masuda, T.; Inaba, Y.; Takeda, Y. Antioxidant mechanism of carnosic acid: Structural identification of two oxidation products. J. Agric. Food Chem. 2001, 49, 5560-5565. [CrossRef] [PubMed]

7. Saito, S.; Okamoto, Y.; Kawabata, J. Effects of alcoholic solvents on antiradical abilities of protocatechuic acid and its alkyl esters. Biosci. Biotechnol. Biochem. 2004, 68, 1221-1227. [CrossRef] [PubMed]

8. Balasundram, N.; Sundram, K.; Samman, S. Phenolic compounds in plants and agri-industrial by-products: Antioxidant activity, occurrence, and potential uses. Food Chem. 2006, 99, 191-203. [CrossRef]

9. Moure, A.; Cruz, J.M.; Franco, D.; Domínguez, J.M.; Sineiro, J.; Domínguez, H.; Núñez, M.J.; Parajó, J.C. Natural antioxidants from residual sources. Food Chem. 2001, 72, 145-171. [CrossRef]

10. Schieber, A.; Stintzing, F.C.; Carle, R. By-products of plant food processing as a source of functional compounds-Recent developments. Trends Food Sci. Technol. 2001, 12, 401-413. [CrossRef]

11. Borguini, R.G.; Torres, E.A.F.S. Tomatoes and tomato products as dietary sources of antioxidants. Food Rev. Int. 2009, 25, 313-325. [CrossRef]

12. Yanagimoto, K.; Lee, K.G.; Ochi, H.; Shibamoto, T. Anti-oxidative activity of heterocyclic compounds found in coffee volatiles produced by Maillard reaction. J. Agric. Food Chem. 2002, 50, 5480-5484. [CrossRef] [PubMed]

13. Higdon, J.V.; Frei, B. Coffee and health: A review of recent human research. Crit. Rev. Food Sci. Nutr. 2006, 46, 101-123. [CrossRef] [PubMed]

14. Tokimoto, T.; Kawasaki, N.; Nakamura, T.; Akutagawa, J.; Tanada, S. Removal of lead ions in drinking water by coffee grounds as vegetable biomass. J. Colloid Interface Sci. 2005, 281, 56-61. [CrossRef] [PubMed]

15. Waterhouse, A.L. Determination of Total Phenolics. In Current Protocols in Food Analytical Chemistry; Wrolstad, R.E., Ed.; John Wiley \& Sons: New York, NY, USA, 2001; Units I; pp. I1.1.1-I1.1.8.

16. Price, M.L.; Butler, L.G. Rapid visual estimation and spectrophotometric determination of tannin content of sorghum grain. J. Agric. Food Chem. 1977, 25, 1268-1273. [CrossRef]

17. Kim, D.O.; Jeong, S.W.; Lee, C.Y. Antioxidant capacity of phenolic phytochemicals from various cultivars of plums. Food Chem. 2003, 81, 321-326. [CrossRef]

18. Chang, S.T.; Wu, J.H.; Wang, S.Y.; Kang, P.L.; Yang, N.S.; Shyur, L.F. Antioxidant activity of extracts from Acacia confuse bark and heart wood. J. Agric. Food Chem. 2001, 49, 3420-3424. [CrossRef] [PubMed]

19. Shyur, L.F.; Tsung, J.H.; Chen, J.H.; Chiu, C.Y.; Lo, C.P. Antioxidant properties of extracts from medicinal plants popularly used in Taiwan. Int. J. Appl. Sci. Eng. 2005, 3, 195-202.

20. Geremu, M.; Tola, Y.B.; Sualeh, A. Extraction and determination of total polyphenols and antioxidant capacity of red coffee (Coffea arabica L.) pulp of wet processing plants. Chem. Biol. Technol. Agric. 2016, 3, 25-30. [CrossRef]

21. Zuorro, A.; Lavecchia, R. Spent coffee grounds as a valuable source of phenolic compounds and bioenergy. J. Clean. Prod. 2012, 34, 49-56. [CrossRef]

22. Yanishkieva-Maslarova, N.V. Inhibiting oxidation. In Antioxidants in Food: Practical Applications; Pokorny, J., Yanishlieva, N., Gordon, M.H., Eds.; Woodhead Publishing Limited: Cambridge, UK, 2001; pp. 22-70.

23. Lee, V.S.Y.; Dou, J.P.; Chen, R.J.Y.; Lin, R.S.; Lee, M.R.; Tzen, J.T.C. Massive accumulation of gallic acid and unique occurrence of myricetin, quercetin, and kaempferol in preparing old oolong black tea. J. Agric. Food Chem. 2008, 56, 7950-7956. [CrossRef] [PubMed]

24. Nadiah, N.I.; Uthumporn, U. Determination of phenolic and antioxidant properties in black tea and spent black tea under various extraction method and determination of catechin, caffeine and gallic acid by HPLC. IJASEIT 2015, 5, 158-164.

25. Vignoli, J.A.; Bassoli, D.G.; Benassi, M.T. Antioxidant activity, polyphenols, caffeine and melanoidins in soluble coffee: The influence of processing conditions and raw material. Food Chem. 2011, 124, 863-868. [CrossRef] 
26. Romdhane, M.B.; Krichen, F.; Ghazal, I.; Semia, E.C.; Haddr, A. Effect of extraction methods on chemical composition. Angiotensin I-converting enzyme inhibitory and antioxidant activity of coffee residue. J. Food Process. Preserv. 2017, 41, 12768-12777. [CrossRef]

27. Farhoosh, R.; Golmovahhed, G.A.; Khodaparast, M.H.H. Antioxidant activity of various extracts of old tea leaves and black tea wastes (Camellia sinensi L.). Food Chem. 2007, 100, 231-236. [CrossRef]

28. Ghafoor, K.; Al-Juhaimi, F.; Choi, Y.H. Effects of grape (Vitis labrusca B.) peel and seed extracts on phenolics, antioxidants and anthocyanins in grape juice. Pak. J. Bot. 2011, 43, 1581-1586.

29. Dalar, A.; Türker, M.; Zabaras, D.; Konczak, I. Phenolic composition, antioxidant and enzyme inhibitory activities of (Eryngium bornmuelleri) leaf. Plant Foods Hum. Nutr. 2014, 69, 30-36. [CrossRef] [PubMed]

30. Zaroug, M.; Orhan, I.E.; Senol, F.S.; Yagi, S. Comparative antioxidant activity appraisal of traditional Sudanese kisra prepared from two sorghum cultivars. Food Chem. 2014, 156, 110-116. [CrossRef] [PubMed]

31. Sir Elkhatim, K.A.; Elagib, R.A.; Hassan, A.B. Content of phenolic compounds and vitamin C and antioxidant activity in wasted parts of Sudanese citrus fruits. Food Sci. Nutr. 2018. [CrossRef]

(C) 2018 by the authors. Licensee MDPI, Basel, Switzerland. This article is an open access article distributed under the terms and conditions of the Creative Commons Attribution (CC BY) license (http:// creativecommons.org/licenses/by/4.0/). 